\title{
ELABORAÇÃO DE MICROESTRUTURAS POROSAS A BASE DE QUITOSANA E QUITINA PARA A ADSORÇÃO DO CORANTE AZUL BRILHANTE
}

\author{
V. M. ESQUERDO ${ }^{1 *}$, T. M. QUINTANA ${ }^{1}$, N. S. S. MARTINS ${ }^{1}$, B. S. FARIAS ${ }^{1}$, L. A. A. PINTO ${ }^{1}$ \\ ${ }^{1}$ Universidade Federal de Rio Grande, Escola de Química e Alimentos \\ *e-mail: nessafurg@ gmail.com
}

\begin{abstract}
RESUMO
A quitosana e a quitina são adsorventes que ganham destaque por serem obtidos de fontes naturais renováveis, porém elas são normalmente utilizadas na forma de pó, possuindo baixa porosidade. A elaboração de microestruturas porosas à base de quitosana e quitina para utilização como adsorvente de corantes em meio aquoso é um estudo relevante. Este trabalho teve como objetivo elaborar microestruturas adsorventes à base de quitosana e quitina com características adequadas para a adsorção do corante azul brilhante em solução aquosa. Foi elaborada uma microestrutura utilizando apenas quitosana e duas microestruturas utilizando quitosana adicionada de quitina em pó e em flocos. Os três adsorventes foram caracterizados por FT-IR, para classificar as principais vibrações dos grupos funcionais, e MEV para observar a presença de microestruturas com superfície megaporosa. $\mathrm{O}$ efeito do $\mathrm{pH}(2,4$ e 6$)$ no percentual de remoção foi avaliado. A diminuição do $\mathrm{pH}$ favoreceu o percentual de remoção $(98,2 \%$ para a microestrutura de quitosana pura, 70,2\% para a microestrutura adicionada de quitina em flocos e $69,5 \%$ para a microestrutura adicionada de quitina em pó). Experimentos de equilíbrio foram realizados em pH 2 demonstrando que as microestruturas são bons materiais adsorventes, pois apesar de uma diminuição da capacidade de adsorção no material adicionado de quitina, foi necessária uma menor quantidade de quitosana para a elaboração das microestruturas, tornando o adsorvente de menor custo.
\end{abstract}

\section{INTRODUÇÃo}

Corantes são aditivos usados em alimentos, bebidas, fármacos e cosméticos para aumentar o apelo, compensar a perda de cor, ajudar na identificação e proteger os componentes sensíveis à luz. O corante triarilmetano azul brilhante é um aditivo solúvel em água que tem sido utilizado em alimentos, medicamentos e cosméticos desde o final de 1800 (BORZELECA, DEPUKAT e HALLAGAN, 1990). Devido a sua baixa taxa de fixação, uma considerável parcela deste corante acaba sendo descartada nos efluentes industriais, o que é prejudicial ao meio ambiente (CRINI e BADOT, 2008). A remoção dos corantes presentes em efluentes é ambientalmente importante, pois, são considerados altamente tóxicos para a vida aquática, afetando processos simbióticos, reduzindo a capacidade de reoxigenação da água, dificultando a passagem de luz solar, e consequentemente, reduzindo a atividade fotossintética (PICCIN et al., 2009).

Por serem altamente solúveis em água e apresentar estrutura complexa, as moléculas dos corantes são muito estáveis, dificultando a remoção por processos convencionais pela baixa eficiência e custos elevados (GUPTA e SUHAS, 2009). A adsorção ganha destaque por ser um método simples e eficiente para a remoção de espécies em soluções líquidas em 
baixas concentrações (KUNZ et al., 2002). Os biopolímeros quitina e quitosana são polissacarídeos formados por unidades monoméricas de glucosamina e $\mathrm{N}$-acetil glucosamina em diferentes proporções (PRASHANTH e THARANATHAN, 2007). Estes biopolímeros vêm sendo explorados para a adsorção de corantes, pois, são matérias-primas obtidas geralmente a partir de resíduos da indústria pesqueira, possuindo boa capacidade de adsorção, alta seletividade, elevada afinidade com uma ampla variedade de corantes e relativo baixo custo (CRINI e BADOT, 2008).

Normalmente a quitosana e quitina são utilizadas na forma de pó, o que acarreta em aspectos negativos, como por exemplo, baixa porosidade e dificuldade de separação das fases após a adsorção (CRINI e BADOT, 2008), existindo assim interesse no desenvolvimento de materiais porosos à base de quitosana e quitina (MIRMOHSENI et al., 2012). $\mathrm{O}$ pH do meio é um fator que influencia diretamente $\mathrm{o}$ processo de adsorção. Além disso, os estudos de equilíbrio, na adsorção de corantes por materiais à base de quitosana e quitina, são de fundamental importância, pois fornecem a relação entre a quantidade de corante adsorvida e a quantidade remanescente na solução em uma temperatura fixa (CRINI e BADOT, 2008).

Este trabalho teve como objetivo elaborar microestruturas à base de quitosana e quitina com características adequadas para a adsorção do corante azul brilhante em solução aquosa. Três microestruturas porosas foram elaboradas e caracterizadas utilizando as técnicas de análise de infravermelho com transformada de Fourier (FT-IR) e microscopia eletrônica de varredura (MEV). $\mathrm{O}$ efeito do $\mathrm{pH}(2,4$ e 6) no percentual de remoção foi avaliado, e na melhor condição foram realizados experimentos de equilíbrio a $25^{\circ} \mathrm{C}$ para os diferentes adsorventes.

\section{MATERIAL E MÉTODOS}

\subsection{Adsorbato}

O corante de grau alimentício azul brilhante, também conhecido como acid blue 9, (índice de cor 42090, massa molar 792,84 g $\mathrm{mol}^{-1}, \lambda_{\text {máx }}=408 \mathrm{~nm}$ ) foi utilizado como adsorbato. Este corante foi fornecido pela empresa Duas Rodas Ind. (Brasil), com pureza de $85 \%$ e sua estrutura química está apresentada na Figura 1.

Figura 1 - Estrutura química do corante azul brilhante

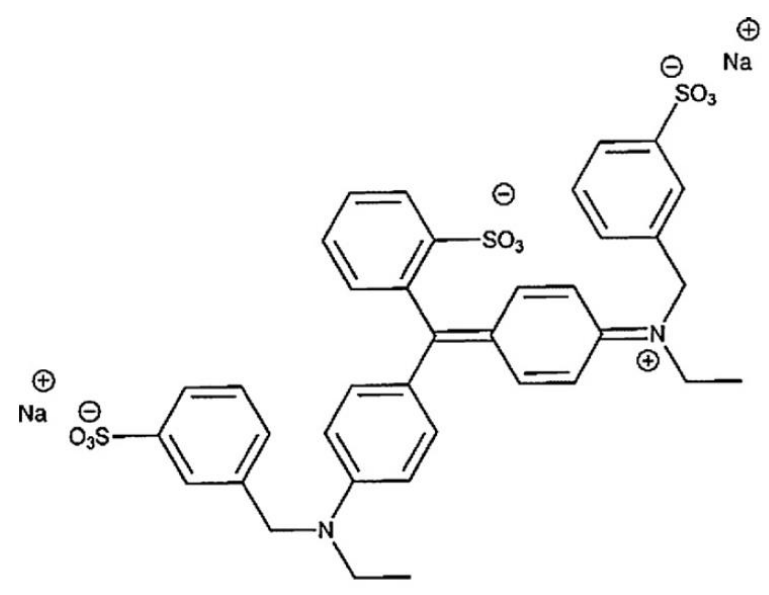

Fonte: Dotto e Pinto (2011).

\subsection{Preparo e caracterização das microestruturas adsorventes}

A quitina e a quitosana utilizadas foram obtidas a partir de resíduos de camarão (Penaeus brasiliensis) fornecidos por indústrias de pescado da cidade de Rio Grande/RS.

Primeiramente os resíduos passaram por uma pré-limpeza, em seguida, procederam-se as etapas de desmineralização, desproteinização e desodorização, para a obtenção da quitina (grau de desacetilação de $45 \%$ ). A quitina foi desacetilada, e a quitosana obtida foi purificada (massa molar de $150 \mathrm{kDa}$ e grau de desacetilação de $86 \%$ ) conforme Weska et al. (2007). Após, a quitosana foi seca em leito de jorro (DOTTO 
et al., 2011), apresentando diâmetro de 70 $\mu \mathrm{m}$. A quitina proveniente do processo (seca em bandeja) apresentou formato de flocos com diâmetro médio de 4,5 mm. Amostras de quitina foram moídas em moinho de facas (Wiley Mill Standard, No. 03, EUA), e peneiradas, utilizando-se o pó na faixa de granulometria de aproximadamente $1 \mathrm{~mm}$.

Para a elaboração das microestruturas, solubilizou-se a quitosana em pó $(2 \% \mathrm{p} / \mathrm{v}) \mathrm{em}$ solução de ácido acético (1\% v/v) por $24 \mathrm{~h} \mathrm{em}$ agitador magnético à temperatura ambiente. Separou-se parte do volume da solução para a obtenção da microestrutura de quitosana pura. Dividiu-se o volume da solução restante, e adicionou-se $1 \mathrm{~g}$ de quitina na forma de flocos a uma amostra, e $1 \mathrm{~g}$ de quitina em pó a outra. Após, as três amostras foram homogeneizadas em agitador mecânico (Dremel, 1100-01, Brasil) por $5 \mathrm{~min}$ a $10000 \mathrm{rpm}$. Posteriormente, as amostras foram vertidas em bandejas e levadas a ultra-freezer (Indrel, IULT 90-D, Brasil), onde permaneceram por $48 \mathrm{~h}$ a $193 \mathrm{~K}$. Após as bandejas foram levadas a um liofilizador (Liobras, L108, Brasil) por $48 \mathrm{~h}$ à temperatura de $219 \mathrm{~K}$ e vácuo de 44 mm de $\mathrm{Hg}$ absolutos.

Os adsorventes tiveram suas características texturais observadas por microscopia eletrônica de varredura (MEV) (Jeol, JSM-6060, Japão), e os grupamentos funcionais foram identificados por análise de infravermelho com transformada de Fourier (FT-IR) (Prestige 21, the 210045, Japão).

\subsection{Ensaios de adsorção}

Nos experimentos de adsorção do corante alimentício azul brilhante pelas microestruturas elaboradas, foi avaliado $\mathrm{o}$ efeito do $\mathrm{pH}(2,4$ e 6). As amostras dos adsorventes $(25 \mathrm{mg})$ foram adicionadas a 80 $\mathrm{mL}$ de água destilada e o $\mathrm{pH}$ foi corrigido através da adição de $10 \mathrm{~mL}$ de soluções tampão fosfato dissódico/ácido cítrico $0,1 \mathrm{~mol}$ $\mathrm{L}^{-1}$. Posteriormente, $10 \mathrm{~mL}$ de solução estoque de corante azul brilhante $\left(1 \mathrm{~g} \mathrm{~L}^{-1}\right)$ foram adicionados às soluções. As soluções foram agitadas a $100 \mathrm{rpm}$ utilizando um agitador termostatizado do tipo de Wagner (Fanem, 315 SE, Brasil), por 24 h à $298 \mathrm{~K}$. Alíquotas da solução foram filtradas (papel filtro Whatmann $\mathrm{n}^{\circ} 40$ ), e a quantidade de corante remanescente foi determinada por espectrofotometria (Quimis Q108 DRM, Brasil) a $408 \mathrm{~nm}$. O percentual de remoção $(\% R)$ foi calculado de acordo com a Equação 1:

$\% R=\frac{C_{0}-C_{f}}{C_{0}} \times 100 \%$

Utilizando o $\mathrm{pH}$ que forneceu os melhores percentuais de remoção, foram realizados experimentos de equilíbrio para verificar a capacidade de adsorção dos três adsorventes. Para isso, soluções estoque dos corantes $\left(1,0 \mathrm{~g} \mathrm{~L}^{-1}\right)$ foram preparadas pela dissolução dos mesmos em água destilada, e tiveram o pH ajustado. Os adsorventes (250 $\mathrm{mg} \mathrm{L}^{-1}$ ) foram adicionadas às soluções de corante em diferentes concentrações iniciais $\left(100,200,300,400,500,600\right.$ e $\left.700 \mathrm{mg} \mathrm{L}^{-1}\right)$. As soluções foram transferidas para frascos com capacidade de $500 \mathrm{~mL}$ e agitadas a 100 rpm em agitador termostatizado tipo Wagner (Fanem, 315 SE, Brasil) por 24 h a 298 K. A concentração dos corantes remanescente nas soluções foi determinada por espectrofotometria e a capacidade de adsorção no equilíbrio $\left(q_{e}\right)$ foi determinada pela Equação 2:

$q_{e}=\frac{C_{0}-C_{e}}{m} \times V$

\section{RESULTADOS E DISCUSSÃO}

\subsection{Microestruturas adsorventes}

A Figura 2 apresenta as imagens fotográficas das microestruturas adsorventes 
formadas, e a Figura 3 apresenta as imagens de MEV dos adsorventes.

Figura 2 - Microestruturas adsorventes de: (a) quitosana pura (b) quitosana e quitina em flocos e (c) quitosana e quitina em pó.

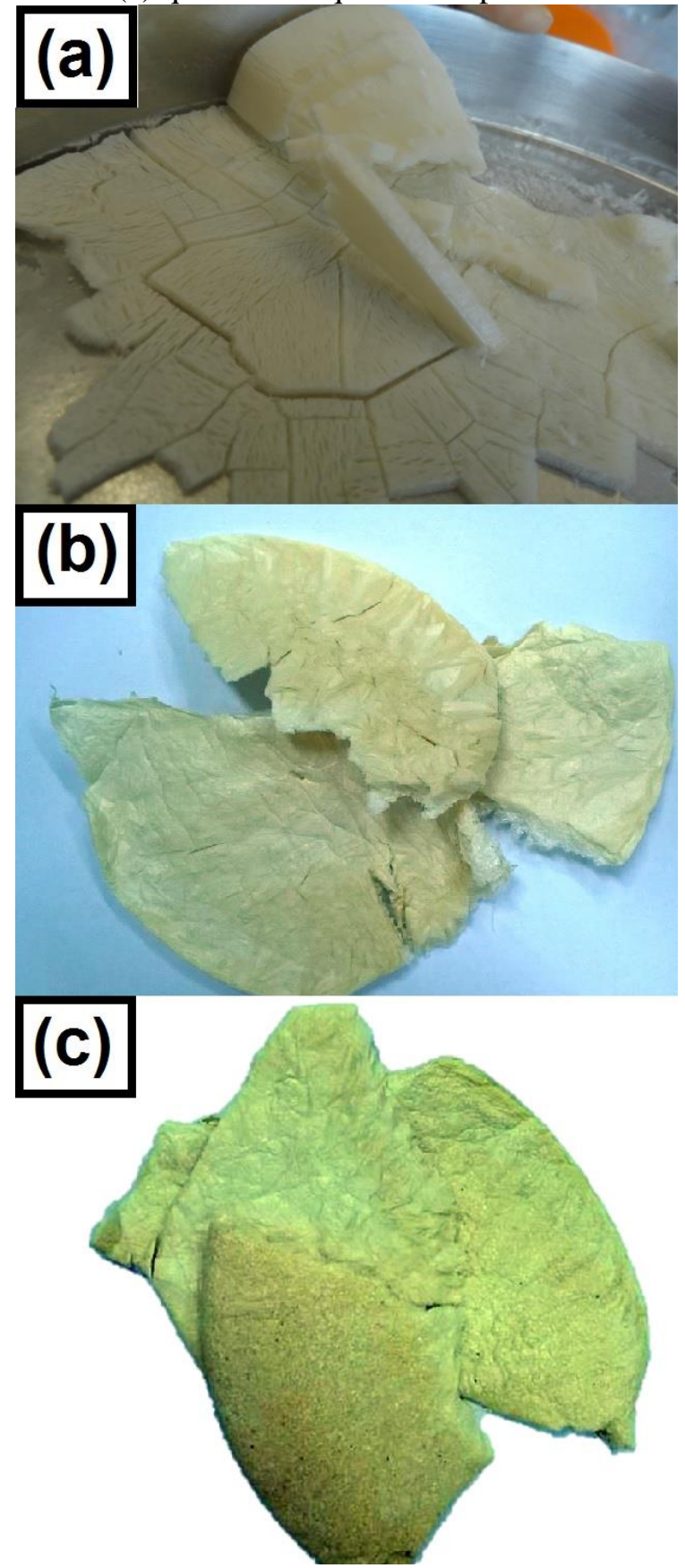

Figura 3 - Microestruturas adsorventes de: (a) quitosana pura (b) quitosana e quitina em flocos e (c) quitosana e quitina em pó.

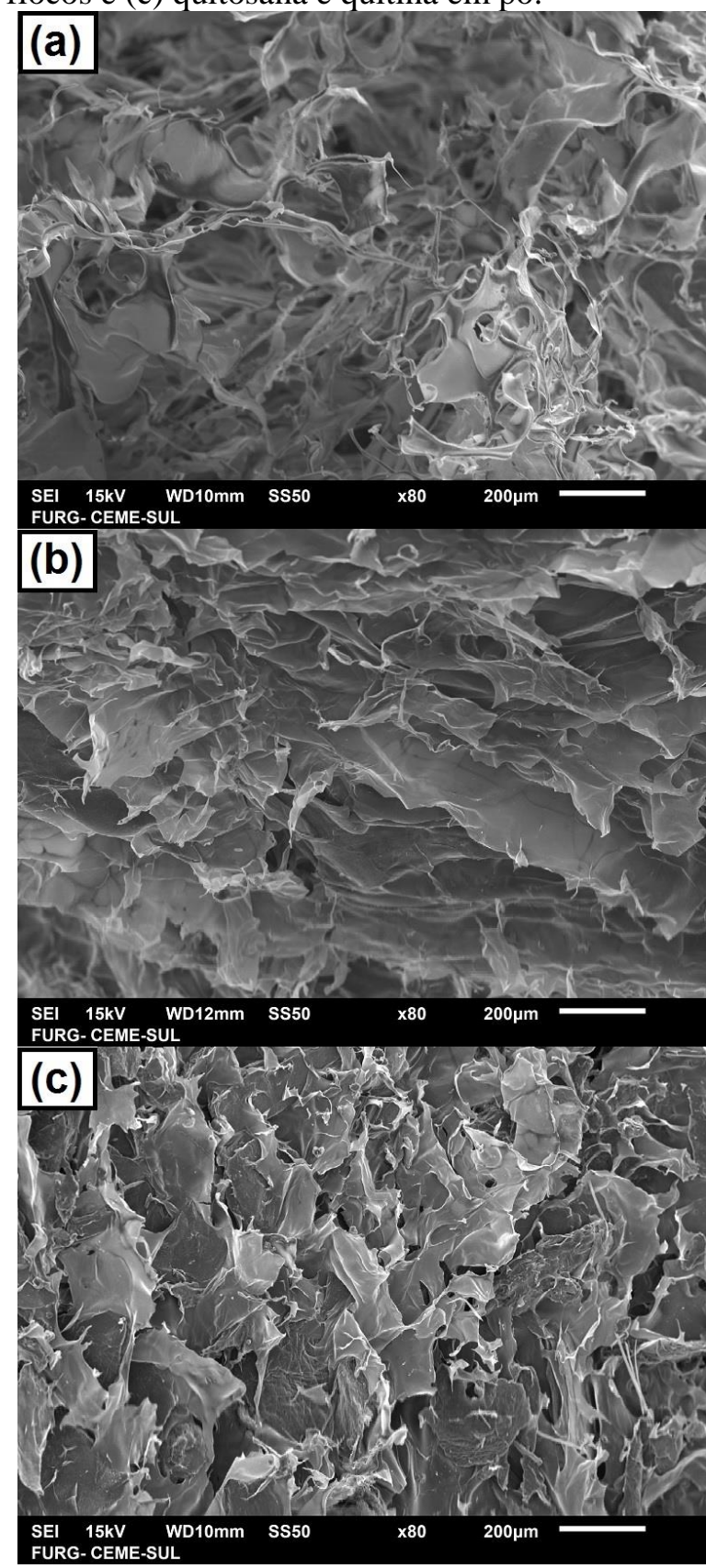

Fonte: Autor (2015)

Fonte: Autor (2015) 
$\mathrm{Na}$ Figura 3 podemos observar que as microestruturas apresentaram-se porosas, com tamanho de poros na ordem de 50-150 $\mu \mathrm{m}$. De acordo com a classificação da IUPAC, poros com tamanho acima de 7,5 $\mu \mathrm{m}$ são denominados megaporos (IUPAC, 2012). Desta forma, pode-se afirmar que foram obtidos adsorventes megaporos. Para adsorção, estruturas megaporosas são interessantes, pois permitem o acesso das moléculas de corante nos sítios internos do material (CRINI e BADOT, 2008). Além disso, pode-se observar que no adsorvente elaborado com quitosana pura (Figuras 2a e 3a) a quantidade de poros é maior, quando comparado aos adsorventes que foram adicionados de quitina (Figura $3 b$ e $3 c$ ). Isso pode ter ocorrido devido a maior massa ocupando o mesmo volume de amostra. Isso fez com que a quitina preenchesse parte dos poros.

A fim de identificar alterações nos grupos funcionais das diferentes amostras de adsorventes, foram realizadas análises por FTIR. A Figura 4 mostra os espectros de FT-IR das microestruturas.

$\mathrm{Na}$ Figura 4, as ligações características da quitosana $\mathrm{N}-\mathrm{H}$ e $\mathrm{O}-\mathrm{H}$ podem ser observados nos picos 3,350 e $3,150 \mathrm{~cm}^{-1}$. O estiramento da ligação $\mathrm{C}-\mathrm{N}$ das amidas pode ser identificado em $1550 \mathrm{~cm}^{-1}$. As deformações angulares de C-O-H e $\mathrm{H}-\mathrm{C}-\mathrm{H}$ aparecem em $1450 \mathrm{~cm}^{-1}$. Em $1100 \mathrm{~cm}^{-1} \mathrm{o}$ estiramento dos grupos amino pode ser identificado. A principal alteração que pode ser observada após a adição da quitina no adsorvente (Figura $4 \mathrm{~b}$ e $4 \mathrm{c}$ ) é o aparecimento do pico em $1900 \mathrm{~cm}^{-1}$. Nesta faixa podem ser vistas as bandas de deformação angular de $\mathrm{C}=\mathrm{O}$ com maior intensidade, comprovando a presença da quitina (CRINI e BADOT, 2008; DOTTO et al., 2013).
Figura 4 - Espetro infravermelho (FT-IR) dos adsorventes a base de: (a) quitosana pura (b) quitosana e quitina em flocos e (c) quitosana e quitina em pó.

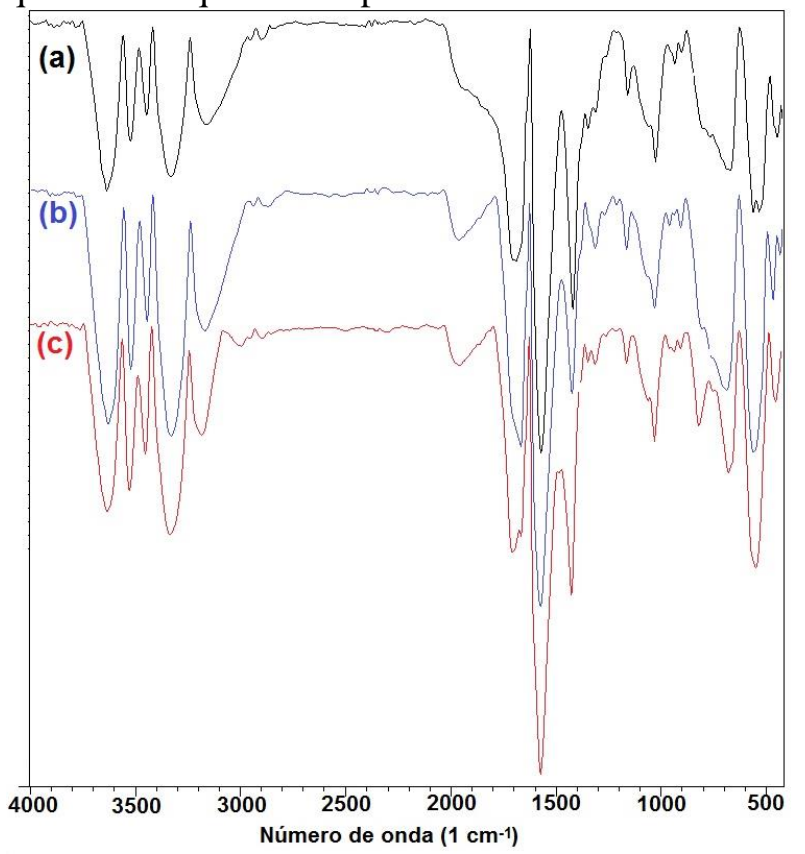

Fonte: Autor (2015)

\subsection{Ensaios de adsorção}

A Figura 5 apresenta a influência do pH no percentual de remoção do corante, para as microestruturas adsorventes elaboradas.

$\mathrm{Na}$ Figura 5, pode-se observar que a adsorção do corante azul brilhante foi favorecida pela redução do $\mathrm{pH}$ de 6 para 2. Os valores máximos obtidos foram de 98,2\% para a microestrutura utilizando quitosana pura, $70,2 \%$ para a microestrutura adicionada de quitina em flocos e $69,5 \%$ para a microestrutura adicionada de quitina em pó, todos em $\mathrm{pH}$ 2. Em menores valores de $\mathrm{pH}$, os íons $\mathrm{H}_{+}$presentes na solução, facilitam a protonação dos grupos amino $\left(\mathrm{NH}_{2}\right)$. Assim, este comportamento pode ser explicado, pois em meio ácido os amino grupos da quitina e quitosana foram protonados, interagindo com os grupamentos sulfonados do corante (CRINI e BADOT, 2008; DOTTO e PINTO, 2011). 
Figura 5 - Percentual de remoção na adsorção utilizando microestruturas a base de: (a) quitosana pura (b) quitosana e quitina em flocos e (c) quitosana e quitina em pó em diferentes valores de $\mathrm{pH}$.

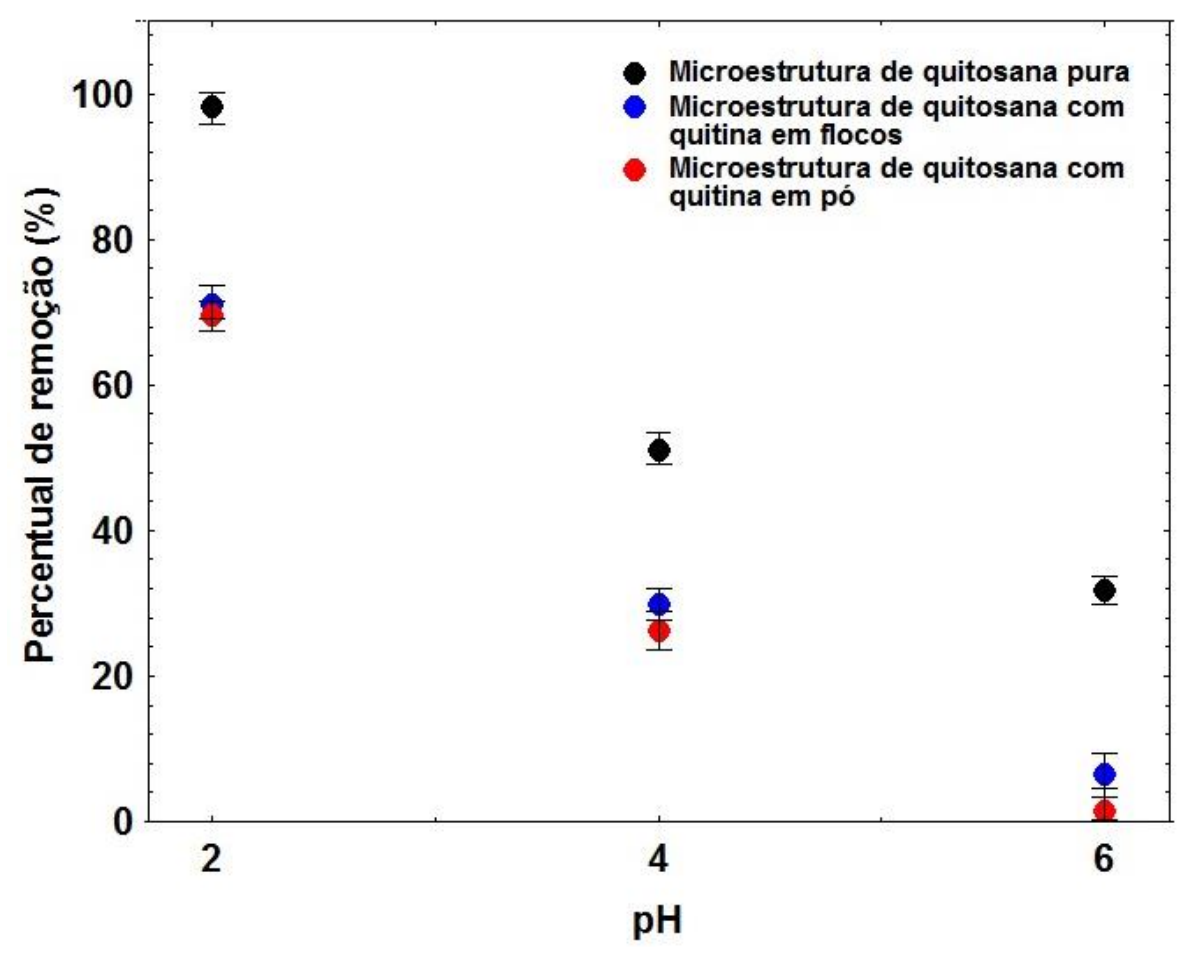

Fonte: Autor (2015)

Além disso, a Figura 5 mostra que a microestrutura de quitosana apresentou maior percentual de remoção em todos os valores de $\mathrm{pH}$. Isto pode ser explicado, levando-se em conta o grau de desacetilação da quitosana $(85 \%)$ que é bem superior ao da quitina (45\%), logo, na quitosana mais amino grupos estão disponíveis para a interação com o corante. A granulometria da quitina não influenciou diretamente no percentual de remoção, onde as diferentes microestruturas de quitosana com quitina apresentaram valores dentro da mesma faixa de variação.

Após verificar o melhor $\mathrm{pH}$ para a adsorção, foram realizados experimentos de equilíbrio utilizando $\mathrm{pH} 2$ e temperatura de $25^{\circ} \mathrm{C}$. A Figura 6 apresenta as curvas experimentais de equilíbrio para a adsorção do corante azul brilhante pelos diferentes adsorventes estudados.

Como pode ser verificado na Figura 6, para todos os adsorventes foram obtidas isotermas do tipo IV, relativa à formação de

multicamadas de adsorbato, onde a primeira camada é formada na superfície do adsorvente e a outra na parede do poro. A formação de multicamadas pode ocorrer quando a molécula do adsorbato tem o diâmetro muito inferior ao tamanho dos poros do adsorvente. Neste estudo o corante utilizado (azul brilhante) possui molécula com diâmetro de aproximadamente 18,0 $\AA$, o que confirma o seu menor diâmetro comparado as microestruturas adsorventes porosas obtidas (Figura 3) (BLÁZQUEZ et al., 2010; BRUNAUER, DEMING e TELLER, 1940; RUTHVEN, 1984). 
Figura 6 - Curvas experimentais de equilíbrio da adsorção do corante azul brilhante por microestruturas a base de: (a) quitosana pura (b) quitosana e quitina em flocos e (c) quitosana e quitina em pó.

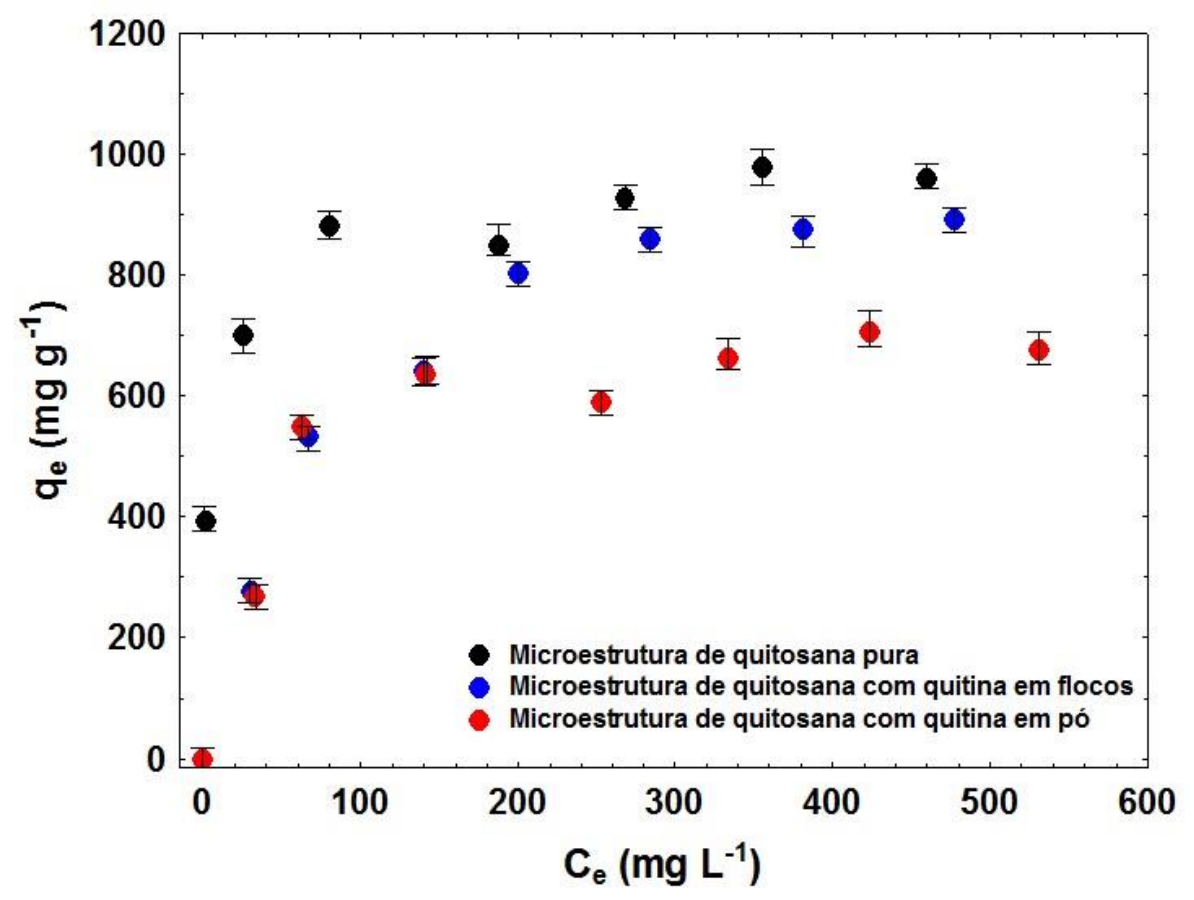

Fonte: Autor (2015)

$\mathrm{Na}$ Figura 6, também pode ser observado que, a microestrutura obtida com quitosana pura apresentou capacidade de adsorção mais elevada, corroborando o comportamento encontrado na influência do $\mathrm{pH}$ (Figura 5). Quanto aos adsorventes adicionados de quitina, a microestrutura elaborada com quitina em flocos teve capacidade de adsorção de $890 \mathrm{mg} \mathrm{g}^{-1}$ e a microestrutura elaborada com quitina em pó $677 \mathrm{mg} \mathrm{g}^{-1}$. Essa diminuição pode ser explicada pela diminuição do diâmetro da quitina, que por ser menor pode ter preenchido os poros, dificultando a ligação do adsorbato à parede do poro. Porém, ambas apresentaram capacidades de adsorção relativamente elevadas. Levando-se em consideração que a quitosana é um adsorvente relativamente caro, pois a transformação de quitina em quitosana demanda o consumo de reagentes e de fontes de aquecimento, gerando um produto final com certo valor agregado, e as microestruturas possuíam cerca de $1 / 3$ da massa de quitina para $2 / 3$ de quitosana, a queda na capacidade de adsorção pode ser balanceada pelo menor quantidade de quitosana para a elaboração das microestruturas.

\section{CONCLUSÃO}

As microestruturas de quitosana pura e quitosana e quitina foram elaboradas. As análises de MEV e FT-IR permitiram observar a presença de uma superfície megaporosa, e classificar as principais vibrações características dos grupos funcionais. Mediante os ensaios de adsorção do corante azul brilhante pelas microestruturas elaboradas, pôde-se verificar que a diminuição do $\mathrm{pH}$ favoreceu o percentual de remoção, obtendo-se os melhores resultados em $\mathrm{pH} 2(98,2 \%$ para a microestrutura utilizando quitosana pura, $70,2 \%$ para a microestrutura adicionada de quitina em flocos e $69,5 \%$ para a microestrutura adicionada de quitina em pó). Experimentos de equilíbrio foram realizados neste $\mathrm{pH}$, e pôde-se observar que as 
microestruturas adicionadas de quitina apresentaram menor capacidade de adsorção (890 $\mathrm{mg} \mathrm{g}^{-1}$ para quitina em flocos e $677 \mathrm{mg}$ $\mathrm{g}^{-1}$ para quitina em pó) quando comparadas a microestrutura contendo apenas quitosana (959 $\mathrm{mg} \mathrm{g}^{-1}$ ). Porém, apesar de inferiores, as capacidades de adsorção foram satisfatórias, visto que foi necessária uma menor quantidade de quitosana para a elaboração das microestruturas, tornando o adsorvente mais barato.

\section{NOMENCLATURA}

\begin{tabular}{|c|c|c|}
\hline Símbolo & Definição & Unidade \\
\hline$\lambda_{\text {máx }}$ & $\begin{array}{l}\text { Comprimento de onda } \\
\text { máximo }\end{array}$ & $\mathrm{nm}$ \\
\hline$q_{e}$ & $\begin{array}{l}\text { Capacidade de } \\
\text { adsorção no equilíbrio }\end{array}$ & $\mathrm{mg} \mathrm{g}^{-1}$ \\
\hline$C_{0}$ & $\begin{array}{l}\text { Concentração inicial } \\
\text { de corante na fase } \\
\text { líquida }\end{array}$ & $\mathrm{mg} \mathrm{L}^{-1}$ \\
\hline$C_{e}$ & $\begin{array}{l}\text { Concentração de } \\
\text { equilíbrio na fase } \\
\text { líquida }\end{array}$ & $\mathrm{mg} \mathrm{L}^{-1}$ \\
\hline$C_{f}$ & $\begin{array}{l}\text { Concentração final de } \\
\text { corante na fase líquida }\end{array}$ & $\mathrm{mg} \mathrm{L}^{-1}$ \\
\hline$m$ & Massa de adsorvente & $\mathrm{g}$ \\
\hline$V$ & Volume da solução & $\mathrm{L}$ \\
\hline$q_{m}$ & $\begin{array}{l}\text { Capacidade total de } \\
\text { adsorção }\end{array}$ & $\mathrm{mg} \mathrm{g}^{-1}$ \\
\hline$\% R$ & $\begin{array}{l}\text { Percentual de } \\
\text { Remoção }\end{array}$ & $\%$ \\
\hline
\end{tabular}

\section{REFERÊNCIAS}

BLÁZQUEZ, G.; CALERO, M.; HERNÁINZ, F.; TENORIO, G.; MARTÍNLARA, M. A. Equilibrium biosorption of lead (II) from aqueous solutions by solid waste from olive-oil production. Chemical Engineering Journal, v. 160, p. 615-622, 2010.
BORZELECA, J. F.; DEPUKAT, K.; HALLAGAN. J. B. Lifetime toxicity/carcinogenicity studies of FD\&C Blue $\mathrm{n}^{\circ} 1$ (brilliant blue FCF) in rats and mice. Food and Chemical Toxicology. v. 28, n. 4, p. 221-234, 1990.

BRUNAUER, S.; DEMING, L. S.; TELLER, E. On a theory of Van der Waals adsorption of gases. Journal of American Chemical Society, v. 62(7), p.1723-1732, 1940.

CRINI, G.; BADOT, P. Application of chitosan, a natural aminopolysaccharide, for dye removal from aqueous solutions by adsorption processes using batch studies: A review of recent literature. Progress in Polymer Science, v. 33, p. 399-447, 2008.

DOTTO, G. L.; PINTO, L. A. A. Adsorption of food dyes onto chitosan: Optimization process and kinetic. Carbohydrate Polymers, v. 84, p. 231-238, 2011.

DOTTO, G. L.; VIEIRA, M. L. G.; GONÇALVES, J. O.; PINTO, L. A. A. Remoção dos corantes azul brilhante, amarelo crepúsculo e amarelo tartrazina de soluções aquosas utilizando carvão ativado, terra ativada, terra diatomácea, quitina e quitosana: Estudos de equilíbrio e termodinâmica. Química Nova, v. 34, p. 1193-1199, 2011.

DOTTO, G. L.; MOURA, J. M.; CADAVAL, T. R. S.; PINTO, L. A. A. Application of chitosan films for the removal of food dyes from aqueous solutions by adsorption. Chemical Engineering Journal, v. 214, p.816, 2013.

GUPTA, V. K.; SUHAS. Application of lowcost adsorbents for dye removal: A review. Journal of Environmental Management., v. 90, p. 2313-2342, 2009. 
International Union of Pure and Applied Chemistry (IUPAC). Gold Book. IUPAC Ed., New York, 2012.

KUNZ, A.; PERALTA-ZAMOTRA, P.; MORAES, S. G.; DURÁN, N. Novas tendências no tratamento de efluentes têxteis. Química Nova, v. 25, n. 1, p. 78-82, 2002.

MIRMOHSENI, A.; DORRAJI, M.; FIGOLI, A.; TASSELLI, F. Chitosan hollow fibers as effective biosorbent toward dye: Preparation and modeling. Bioresource Technology, v. 121, p. 212-220, 2012.

PICCIN, J. S.; VIEIRA, M. L. G.; GONÇALVES, J. O.; DOTTO, G. L.; PINTO, L. A. A. Adsorption of FD\&C Red No. 40 by chitosan: Isotherms analysis. Journal of Food Engineering, v. 95, p. 1620, 2009.

PRASHANTH, K. V. H.; THARANATHAN, R. N. Chitin/chitosan: modifications and their unlimited application potential: an overview. Food Science \& Technology, v. 18, p. 117131, 2007.

RUTHVEN, D. M. Principles of Adsorption and Adsorption Processes. John Wiley \& Sons, New York, 1984.

WESKA, R.; MOURA, J.; BATISTA, L.; RIZZI, J.; PINTO L. A. A. Optimization of deacetylation in the production of chitosan from shrimp wastes: Use of response surface methodology. Journal of Food Engineering, v. 80, p. 749-753, 2007.

\section{AGRADECIMENTOS}

Os autores agradecem a CAPES (Coordenação de aperfeiçoamento de pessoal de nível superior), CNPq (Conselho nacional de desenvolvimento científico e tecnológico),
FAPERGS (Fundação de Amparo a Pesquisa do Estado do Rio Grande do Sul) e a FURG (Universidade Federal do Rio Grande) pelo auxílio financeiro, e também ao CEMESUL/FURG (Centro de Microscopia Eletrônica da Metade Sul) pelo suporte analítico. 